\title{
Measurement of turbulent electron temperature fluctuations on the ASDEX Upgrade tokamak using correlated electron cyclotron emission
}

\author{
Citation for published version (APA): \\ Freethy, S. J., Conway, G. D., Classen, I. G. J., Creely, A. J., Happel, T., Köhn, A., Vanovac, B., \& White, A. E. \\ (2016). Measurement of turbulent electron temperature fluctuations on the ASDEX Upgrade tokamak using \\ correlated electron cyclotron emission. Review of Scientific Instruments, 87(11), 1-3. [11E102]. \\ https://doi.org/10.1063/1.4958908, https://doi.org/10.1063/1.4958908
}

DOI:

$10.1063 / 1.4958908$

$10.1063 / 1.4958908$

Document status and date:

Published: 01/11/2016

\section{Document Version:}

Publisher's PDF, also known as Version of Record (includes final page, issue and volume numbers)

\section{Please check the document version of this publication:}

- A submitted manuscript is the version of the article upon submission and before peer-review. There can be important differences between the submitted version and the official published version of record. People interested in the research are advised to contact the author for the final version of the publication, or visit the DOI to the publisher's website.

- The final author version and the galley proof are versions of the publication after peer review.

- The final published version features the final layout of the paper including the volume, issue and page numbers.

Link to publication

\footnotetext{
General rights

- You may freely distribute the URL identifying the publication in the public portal. follow below link for the End User Agreement:

www.tue.nl/taverne

\section{Take down policy}

If you believe that this document breaches copyright please contact us at:

openaccess@tue.nl

providing details and we will investigate your claim.
}

Copyright and moral rights for the publications made accessible in the public portal are retained by the authors and/or other copyright owners and it is a condition of accessing publications that users recognise and abide by the legal requirements associated with these rights.

- Users may download and print one copy of any publication from the public portal for the purpose of private study or research.

- You may not further distribute the material or use it for any profit-making activity or commercial gain

If the publication is distributed under the terms of Article 25fa of the Dutch Copyright Act, indicated by the "Taverne" license above, please 


\section{Measurement of turbulent electron temperature fluctuations on the ASDEX Upgrade tokamak using correlated electron cyclotron emission}

S. J. Freethy, G. D. Conway, I. Classen, A. J. Creely, T. Happel, A. Köhn, B. Vanovac, and A. E. White

Citation: Review of Scientific Instruments 87, 11E102 (2016);

View online: https://doi.org/10.1063/1.4958908

View Table of Contents: http://aip.scitation.org/toc/rsi/87/11

Published by the American Institute of Physics

\section{Articles you may be interested in}

A correlation electron cyclotron emission diagnostic and the importance of multifield fluctuation measurements for testing nonlinear gyrokinetic turbulence simulations

Review of Scientific Instruments 79, 103505 (2008); 10.1063/1.2981186

Measurements of core electron temperature and density fluctuations in DIII-D and comparison to nonlinear gyrokinetic simulations

Physics of Plasmas 15, 056116 (2008); 10.1063/1.2895408

Validation of nonlinear gyrokinetic simulations of L- and I-mode plasmas on Alcator C-Mod Physics of Plasmas 24, 056104 (2017); 10.1063/1.4977466

Core turbulence behavior moving from ion-temperature-gradient regime towards trapped-electron-mode regime in the ASDEX Upgrade tokamak and comparison with gyrokinetic simulation

Physics of Plasmas 22, 032503 (2015); 10.1063/1.4914153

Experimental observation of turbulence transition and a critical gradient threshold for trapped electron mode in tokamak plasmas

Physics of Plasmas 23, 060702 (2016); 10.1063/1.4953427

Study of the effects of the perpendicular velocity gradient on a Doppler backscattering system using a 2D full wave code

Physics of Plasmas 24, 012501 (2017); 10.1063/1.4973553

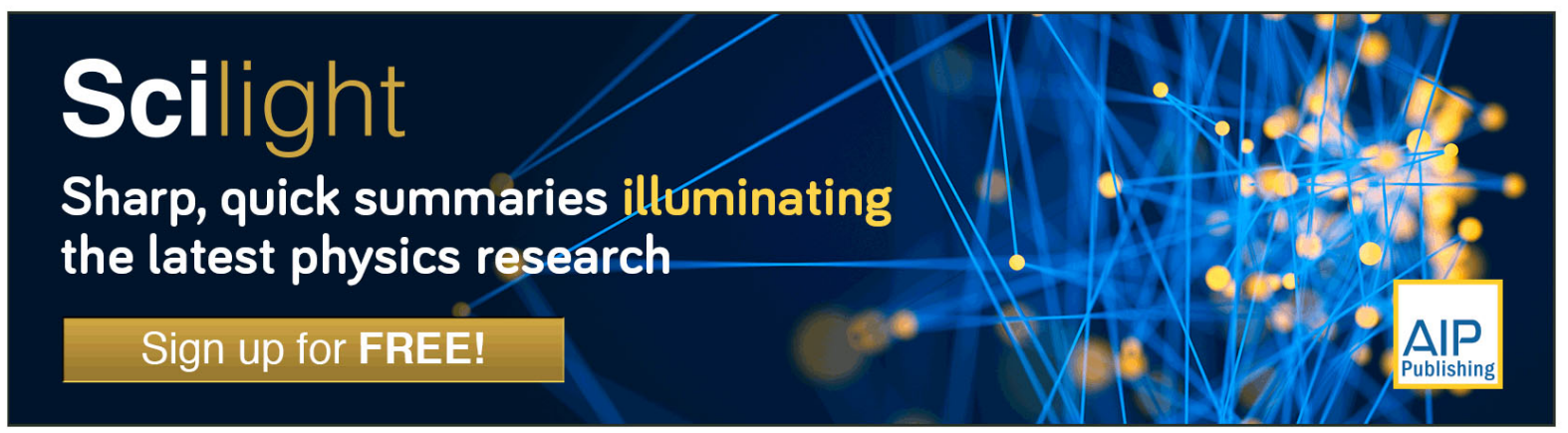




\title{
Measurement of turbulent electron temperature fluctuations on the ASDEX Upgrade tokamak using correlated electron cyclotron emission
}

\author{
S. J. Freethy, ${ }^{1,2, a)}$ G. D. Conway, ${ }^{1}$ I. Classen, ${ }^{3}$ A. J. Creely, ${ }^{2}$ T. Happel, ${ }^{1}$ A. Köhn, ${ }^{1}$ \\ B. Vanovac, ${ }^{3}$ and A. E. White ${ }^{2}$ \\ ${ }^{1}$ Max Planck Institute for Plasma Physics, 85748 Garching, Germany \\ ${ }^{2}$ Plasma Science and Fusion Center, Massachusetts Institute of Technology, Cambridge, \\ Massachusetts 02139, USA \\ ${ }^{3}$ FOM Institute DIFFER, 5612 AJ Eindhoven, The Netherlands
}

(Presented 7 June 2016; received 3 June 2016; accepted 20 June 2016; published online 19 July 2016)

\begin{abstract}
Turbulent temperature fluctuations are measured on the ASDEX Upgrade tokamak using pairs of closely spaced, narrow-band heterodyne radiometer channels and a standard correlation technique. The pre-detection spacing and bandwidth of the radiometer channel pairs is chosen such that they are physically separated less than a turbulent correlation length, but do not overlap. The radiometer has 4 fixed filter frequency channels and two tunable filter channels for added flexibility in the measurement position. Relative temperature fluctuation amplitudes are observed in a helium plasma to be $\delta T / T=(0.76$ $\pm 0.02) \%$, $(0.67 \pm 0.02) \%$, and $(0.59 \pm 0.03) \%$ at normalised toroidal flux radius of $\rho_{\text {tor }}=0.82$, 0.75, and 0.68, respectively. Published by AIP Publishing. [http://dx.doi.org/10.1063/1.4958908]
\end{abstract}

\section{INTRODUCTION}

For the design of future fusion reactors, a physics based understanding of the heat loss channels is an essential element. It is now accepted that the anomalously high heat transport observed in tokamaks is due to the turbulent fluctuations driven by the drift-wave like instabilities in the plasma. ${ }^{1}$ Much progress has been made over the past few decades in understanding and modelling the underlying turbulent mechanisms and large gyro-kinetic modelling codes are now often able to reproduce experimental heat fluxes within error bars (see, for example, Refs. 2 and 3). Validation of their predictions against measurements of the underlying turbulent micro-structure, such as fluctuation amplitude, correlation length, fluctuation phase relations, and spectral index, can serve to help refine and reduce these models further.

Under regular tokamak conditions, core turbulent electron temperature fluctuations are sufficiently broadband $(\sim 0.5 \mathrm{MHz})$ and low-amplitude $(\sim 1 \%)$ that a conventional radiometer is fundamentally unable to detect them, and thus, correlation techniques are required to further extract the signals. ${ }^{4-8}$ This situation arises, as can be seen from Equation (1), from the fact that to increase the sensitivity of a radiometer one must either decrease the video bandwidth, $B_{\mathrm{vid}}$, or increase the pre-detection bandwidth, $B_{\mathrm{IF}}$. Limits are set on $B_{\mathrm{vid}}$ by the fluctuation bandwidth and on $B_{\mathrm{IF}}$ by the spatial scale of the turbulence and the linewidth of the ECE,

$$
\frac{\delta T_{\mathrm{e}}}{T_{\mathrm{e}}}>\sqrt{\frac{B_{\mathrm{vid}}}{B_{\mathrm{IF}}}} .
$$

Note: Contributed paper, published as part of the Proceedings of the 21st Topical Conference on High-Temperature Plasma Diagnostics, Madison, Wisconsin, USA, June 2016.

a)E-mail: simon.freethy @ipp.mpg.de
The first use of cross-correlation to measure temperature fluctuations utilised two radiometer channels with differing lines of sight to the same volume of plasma. ${ }^{5}$ The two lines of sight ensured that the thermal noise fluctuations were uncorrelated, while the common temperature fluctuations remained correlated. ${ }^{4}$ Later, the same line of sight was used and closely spaced, non-overlapping frequency channels served to separate thermal noise from temperature fluctuations. ${ }^{6}$ Here we describe a Correlation Electron Cyclotron Emission (CECE) radiometer of the latter type which has allowed, for the first time, measurements of turbulent temperature fluctuations on ASDEX Upgrade (AUG) and the first turbulent temperature fluctuations in helium plasmas.

\section{CORRELATION ECE DIAGNOSTIC}

A Correlation Electron Cyclotron Emission (CECE) diagnostic utilises cross-correlation in order to be able to measure small, broadband temperature fluctuations. Defining a pair of series of fluctuating ECE power (i.e., with zero mean) as $\{x(t), y(t)\}$ and their corresponding one-sided cross-spectral density functions $\left\{G_{x}(f), G_{y}(f)\right\}$, then we can define the coherence function $\gamma(f)$ as ${ }^{9}$

$$
\gamma(f)=\frac{\left|G_{x y}(f)\right|}{\sqrt{G_{x}(f) G_{y}(f)}} .
$$

$G_{x}(f)$ is estimated from an ensemble average of $N$ independent time records. The temperature fluctuation level up to the limit $f^{\prime}$ can then be calculated by the integral of the coherence over the video bandwidth,

$$
\left(\frac{\delta T_{\mathrm{e}}}{T_{\mathrm{e}}}\right)^{2}=\frac{1}{B_{\mathrm{IF}}} \int_{0}^{f^{\prime}} \gamma(f) d f .
$$

The cross-correlation allows further averaging to be performed without reducing the video bandwidth of either signals. The 


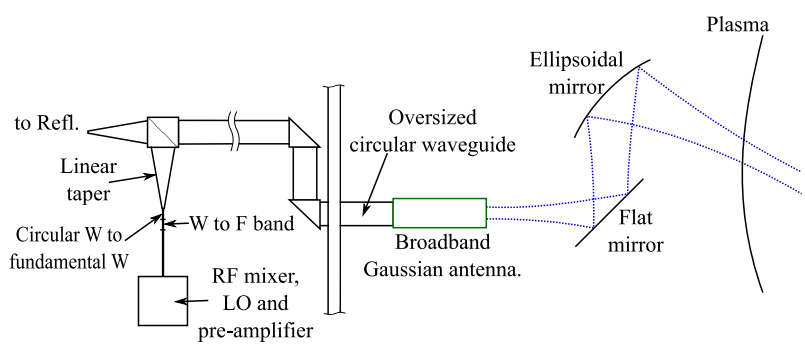

FIG. 1. Schematic showing the optical setup for the correlation ECE. The optical path is shared by the ASDEX-Upgrade steerable Doppler reflectometers.

sensitivity of such a radiometer is then given by

$$
\frac{\delta T_{\mathrm{e}}}{T_{\mathrm{e}}}>\left(\frac{B_{\mathrm{vid}}}{2 \Delta t}\right)^{1 / 4}\left(\frac{2}{B_{\mathrm{IF}}}\right)^{1 / 2} .
$$

The correlation ECE radiometer at AUG is installed on an optical front end which was made for the AUG steerable Doppler reflectometer. ${ }^{10}$ Plasma radiation is focussed by a steerable elliptical mirror into a smooth-bore broad-band Gaussian-beam antenna, as shown in Fig. 1. The internal bore of the antenna is $25 \mathrm{~mm}$ long and varies in radius from $19 \mathrm{~mm}$ to $28 \mathrm{~mm}$ at the mouth. ${ }^{10}$ The antenna is then coupled to a $38 \mathrm{~mm}$ oversized waveguide, which is in turn coupled to a $3 \mathrm{~dB}$ splitter in order that the reflectometer and CECE can operate simultaneously. After the splitter, the oversized waveguide is tapered down in stages to fundamental F-band waveguide and passed through a sideband filter between 105 and $113 \mathrm{GHz}$ or 117 and $125 \mathrm{GHz}$. This forms a hybrid waveguide-quasioptical system with the potential for later performing the correlation analysis between the reflectometer and the CECE channels. Fig. 2 shows the electronic schematic for the receiver. After the sideband filter, the signal is passed through a Millitech MSH08 x2 subharmonic mixer which is powered by a Millitech GDV-15 Gunn-varactor tuned local oscillator (LO) which may be tuned in the range $57.5 \mathrm{GHz} \pm 900 \mathrm{MHz}$. This tuning allows flexibility in the measurement positions.

A combination of power splitters and filters make up the CECE filter bank and the diagnostic has four fixed frequency pre-detection filters which can be easily modified, but typically consist of filters centred around 4.000, 4.250, 8.000, and $8.250 \mathrm{GHz}$ and of 100 or $200 \mathrm{MHz}$ bandwidth. The other two channels may consist of either 100 or $200 \mathrm{MHz}$ bandwidth YiG filters whose centre frequencies are tunable in the range

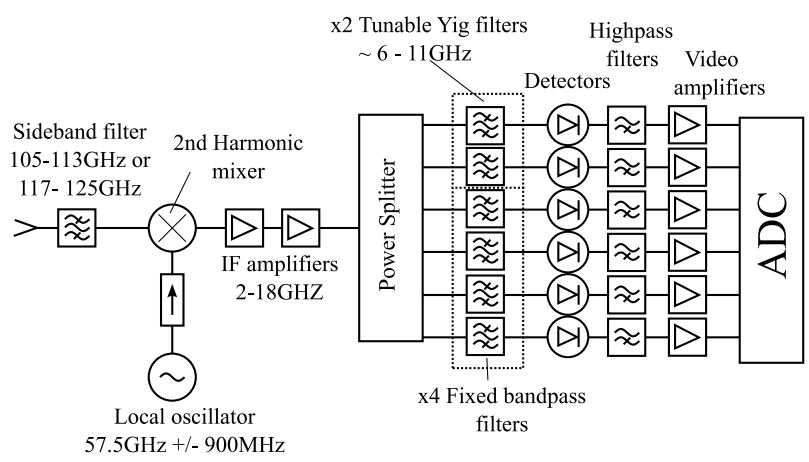

FIG. 2. A schematic of the CECE electronics. A filter bank includes 4 fixed and 2 tunable narrow-band filters.
6-12 GHz and allow important flexibility in the measurement position. The filters are controllable remotely over Ethernet via a "Control By Web" X-312-I analogue output module.

CECE is sensitive to comparatively long wavelength fluctuations relevant for studying Ion Temperature Gradient (ITG) and Trapped Electron Mode (TEM) turbulence. The calculation of the sensitivity of the diagnostic as a function of wavelength is described by Bravenec ${ }^{11}$ and is completely defined by the spatial volume of the measurement in the plasma. For CECE the radial resolution is set by a combination of the broadening mechanisms for the ECE line radiation (predominantly the relativistic mass change as a function of electron energy and the re-absorption of the ECE radiation by the plasma ${ }^{12}$ ) and the filter bandwidth and spacing. The perpendicular wavelength limit is set by the Gaussian beam width at the measurement position. For the current setup, the 1/e electric field radius of the Gaussian beam $w_{\text {meas }}$ between $\rho_{\text {tor }}$ of $0.7-0.9$ is approximately $3.7 \mathrm{~cm}$, giving a perpendicular wavevector limit $k_{\perp, \lim }=2 \sqrt{2} / w_{\text {meas }}$ of $0.76 \mathrm{~cm}^{-1} . w_{\text {meas }}$ will be reduced to $2.0 \mathrm{~cm}$ in the next experimental campaign with the installation of a new focussing mirror, giving an increased $k_{\perp \text {,lim }}$ limit of $1.4 \mathrm{~cm}^{-1}$. In units of the ion Larmor radius $\rho_{i}$, these translate to a $k_{\perp} \rho_{i}$ value of 0.15 and 0.28 , respectively. Radially, pairs of frequency channels are spaced $2-4 \rho_{i}$, within the expected radial correlation length for the turbulence of between 5 and $10 \rho_{i} \cdot{ }^{13}$

\section{RESULTS}

In order to demonstrate the capability of this diagnostic, we present here the measurements of broadband temperature fluctuations that were made in a helium plasma with magnetic field of $2.5 \mathrm{~T}$, plasma current of $800 \mathrm{kA}$, core line-averaged density of $2.1 \times 10^{19} \mathrm{~m}^{-3}, 0.52 \mathrm{MW}$ of Ohmic heating, and $0.67 \mathrm{MW}$ of electron cyclotron resonance heating.

Fig. 3 shows the magnitude of $\gamma(f)$ for three channel pairings. The integrated fluctuation levels are $\delta T / T=(0.76$ $\pm 0.02) \%,(0.67 \pm 0.02) \%$, and $(0.59 \pm 0.03) \%$ up to $100 \mathrm{kHz}$ and at normalised toroidal flux radius of $\rho_{\text {tor }}=0.82,0.75$, and

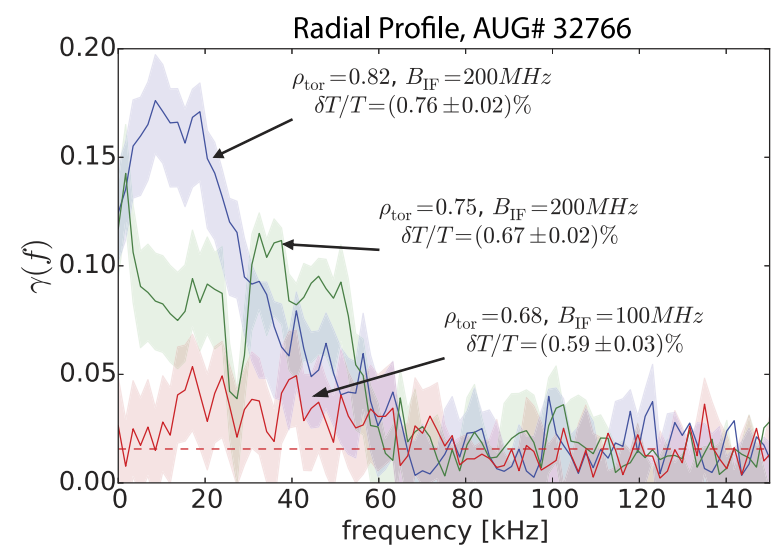

FIG. 3. The coherence between neighbouring frequency channel pairs for a helium L-mode discharge. The red dashed line indicates the statistical noise limit, $1 / \sqrt{N}$, and the shaded regions indicate the uncertainties. There is no measurable coherence between non-neighbouring channels, implying a local measurement. 
0.68 , respectively. These data have been averaged over $2 \mathrm{~s}$ of the plasma stationary phase resulting in a relatively low statistical noise level for this type of measurement, the statistical noise limit, $1 / \sqrt{N}$, being shown as a horizontal red dashed line. No measurable coherence is found between channels which are not in a pair, implying turbulence-like radial scales. The spectral shape for each pair is broadband and is not made up of many smaller coherent structures, as can be tested by altering the frequency resolution of the coherence. The upper limit in frequency is given by $\left(v_{E \times B}+v_{\mathrm{ph}}\right) k_{\perp, \lim } / 2 \pi$.

For CECE measurements to be representative of temperature fluctuations, the plasma must be sufficiently optically thick such that fluctuations in density do not lead to significant fluctuations in the measured radiation temperature. A discussion on the effect of optical depth on the measurement of temperature fluctuations can be found in the work of Peters. ${ }^{14}$ For our three measurement pairs at $\rho_{\text {tor }}=0.82$, 0.75 , and 0.68 the optical depths are 3.0, 4.1, and 5.4, respectively. Density fluctuations in this region are estimated to be $\delta n_{\mathrm{e}} / n_{\mathrm{e}} \simeq 0.5 \%$. If we make the conservative assumption of $\delta n / n=2 \%$, then the maximum apparent fluctuation in radiative brightness due to the modulation of the optical depth is $0.16 \%, 0.07 \%$, and $0.02 \%$, respectively. This is assuming no wall reflections, which may act to reduce these values further. These values are at least a factor of 4.8 lower than the measured fluctuation amplitudes reported. Contributions to the measured fluctuation levels from refractive effects may also be ignored since at these densities a $2 \%$ fluctuation in density leads to a $0.1 \%$ change in refractive index.

\section{CONCLUSIONS}

Correlation techniques can be used on radiometers with closely spaced, narrow-band filter pairs to measure low level $(<1 \%)$ broadband $(<0.5 \mathrm{MHz})$ electron temperature fluctuations associated with plasma turbulence in the core of a tokamak fusion experiment. An application of this frequency decorrelation method had been designed and built for the ASDEX Upgrade tokamak. This diagnostic shares an optical path with a reflectometer, via a novel hybrid waveguidequasioptical transmission line, and is sensitive to wavenumbers $k_{\perp}$ up to $0.76 \mathrm{~cm}^{-1}$. An upgrade to the focussing mirror will improve this by nearly a factor of 2 to $k_{\perp}$ up to $1.4 \mathrm{~cm}^{-1}$. The coupled optics provides the potential of later performing correlation analysis between reflectometer and CECE channels.

Measurements in helium plasmas have been made at three radial locations simultaneously, providing a profile of the temperature fluctuation amplitude in the outer core of an ECRH heated L-mode plasma. These measurements were determined to be local, un-influenced by effects of refraction and optically thick, meaning that the contribution to the radiative temperature fluctuations from density fluctuations is small. Further, the measurements show a broadband structure which is not the effect of many smaller coherent structures from, for example, MHD modes. Currently, the work is under way to compare the fluctuation spectra to experimental predictions using gyro-kinetic codes.

\section{ACKNOWLEDGMENTS}

This work is supported by the US DOE under Grant No. DE-SC0006419 and was performed in the framework of the Helmholtz Virtual Institute on Plasma Dynamical Processes and Turbulence Studies using Advanced Microwave Diagnostics. It has also been carried out within the framework of the EUROfusion Consortium and has received funding from the Euratom research and training programme 2014-2018 under Grant Agreement No. 633053. The views and opinions expressed herein do not necessarily reflect those of the European Commission.

\footnotetext{
${ }^{1}$ W. Horton, Rev. Mod. Phys. 71, 735 (1999).

${ }^{2}$ D. Told, F. Jenko, F. Casson, E. Fable, and ASDEX Upgrade Team, Phys. Plasmas 20, 122312 (2013).

${ }^{3}$ T. Goeler, A. White, D. Told, F. Jenko, C. Holland, and T. Rhodes, Phys. Plasmas 21, 122307 (2014).

${ }^{4}$ C. Cima, Il Nuovo Cimento D 16, 359 (1994).

${ }^{5}$ S. Sattler and H. Hartfuss, Plasma Phys. Controlled Fusion 35, 1285 (1993).

${ }^{6}$ C. Watts, R. Gandy, T. Rempel, and G. Cima, Rev. Sci. Instrum. 66, 451 (1995).

${ }^{7}$ A. White et al., Rev. Sci. Instrum. 79, 103505 (2008).

${ }^{8}$ N. T. Howard, C. Sung, and A. E. White, Rev. Sci. Instrum. 85, $11 \mathrm{D} 811$ (2014).

${ }^{9}$ J. Bendat and A. Piersol, Measurement and Analysis of Random Data, 1st ed. (John Wiley \& Sons, 1966).

${ }^{10} \mathrm{~T}$. Happel et al., in Proceedings of 10th International Reflectometry Workshop, 2011.

${ }^{11}$ R. Bravenec, Rev. Sci. Instrum. 66, 802 (1995).

${ }^{12}$ M. Bornatici, R. Cano, O. D. Barbieri, and F. Engelmann, Nucl. Fusion 23, 1153 (1983).

${ }^{13}$ T. L. Rhodes et al., Phys. Plasmas 9, 2141 (2002).

${ }^{14}$ M. Peters and P. Mantica, Nucl. Fusion Lett. 35, 873 (1995).
} 